\title{
Effect of Actinobacteria and Glomus fasiculatum against Fusarium oxysporum f. sp. lycopersici in Tomato Plant
}

\author{
Anusha Suresh Gadag ${ }^{1}$ and P.U. Krishnaraj ${ }^{2}$ \\ ${ }^{1}$ Molecular Biology and Biotechnology, University of Agricultural Sciences, \\ Dharwad, Karnataka, India \\ ${ }^{2}$ Department of Agriculture Microbiology, College of Agriculture, Vijayapur, University \\ Agricultural Sciences, Dharwad, India \\ *Corresponding author
}

\begin{abstract}
A B S T R A C T
Keywords

Actinobacteria,

Glomus

fasiculatum,

Tomato.

Article Info

Accepted:

04 July 2017

Available Online:

10 September 2017

Fusarium oxysporum f. sp. lycopersici is a soil-borne plant pathogen responsible for the development of Fusarium wilt which is one of the most important and destructive fungal plant diseases worldwide. The pathogenic strain of Fusarium oxysporum f. sp. lycopersici is isolated from the infested plant samples of tomato stem. The identification and confirmation of the isolate were done based on cultural characteristics, pathogenicity test. Out of eighty, Actinobacteria isolates which were collected from Agricultural College, Dharwad, 3 isolates (AUDT 626, AUDT 699 and AUDT 693) were showed a siginificant zone of inhibition $30.99 \mathrm{~mm}$ against Fusarium oxysporum f. sp. lycopersici. Glomus fasiculatum culture applied to the tomato plant showed $58.8 \%$ root colonization along with AUDT 622. Under challenge inoculation with a pathogen, AUDT 626 and both AUDT 626 and $G$. fasiculatum showed significant control of the wilt disease of tomato. In the present study AUDT 626 with G. fasiculatum showed $100 \%$ disease control with root length of $3.18 \mathrm{~cm}$, shoot length $16.9 \mathrm{~cm}$ and total dry weight of $80 \mathrm{mg}$ compared to disease control plant.
\end{abstract}

\section{Introduction}

Fusarium wilt of tomato caused by Fusarium oxysporum f. sp. lycopersici is a most important fungal disease of tomato growing areas in worldwide. The pathogen is soil borne and causes wilt which leads to root and basal stem deterioration and results in wilting of the plant. Browning of the vascular tissue is proof of Fusarium wilt. This pathogen persists in soil without a host for many years.

As a result of extensive use of chemical pesticide, several insects and pathogens have developed the resistance to these chemical pesticides (Ntalli and Spiroudi, 2011). Therefore usage of microbial inoculant as disease suppressive or resistant agents and as plant growth promoting agents are the best alternate solution to the use of chemical pesticides and fertilisers. Arbuscular mycorrhiza fungi are an essential component of the rhizosphere, and they cause beneficial effects on growth and yield of different crops. AM fungi ( $G$. fasiculatum) improve nutrients uptake example nitrogen, phosphorus, micronutrient and others. It also plays an important role in disease tolerance and to 
decrease soil pathogen incidence from genera such as Fusarium, Macrophomina, Phytopthara, Pyrthium, and Rhizoctonia (Cornado et al., 2013). Actinobacteria is one of the important sources of many biologically active components such as metabolites, alkaloids, enzymes, antibiotics, etc. In many areas, actinobacteria act as biocontrol tool against many plant pathogen such as Alternaria solani, Alternaria alternate, Fusarium solani, Phytopthara megasperma, Verticillium dahlia and saccharomyces cervisiae etc. (Aghighi et al., 2004) and can colonize plant surface, antibiosis against plant pathogens, synthesis of extracellular enzymes and the degradation of phytotoxins. Nawar, (2016) used the arbuscular mycorrhiza and actinobacteria isolates as bio-inoclum for growth promotion and biocontrol of damping off disease caused by Rhizoctonia solani. Therefore, the present study on the biocontrol activity of actinobacteria and arbuscular mycorrhiza against Fusarium oxysoprum f. sp. lycopersici on tomato plant growth parameter and disease resistance were done.our study further provide insight in biocontrol research.

\section{Material and Methods}

\section{Sample collection}

The collection of tomato plants which are infected by Fusarium wilt is done from fields of University of Agriculture Science, Dharwad, India. A soil sample from the rhizosphere of tomato plant showing typical wilt symptoms is collected from the field. A part of them is labelled and packed in polyethene bags and stored in a cold room till they are used for the isolation of the fungus.

\section{Isolation of Fusarium and pathogenicity}

Fusarium is isolated from stem and root tissues of infected tomato plants. Sections of the lateral stem are surface sterilised with $1 \%$
$\mathrm{NaOCl}$ solution for 2 min and then stems washed three times in sterile distilled water and blotted on sterile filter paper to remove excess water. Tissue pieces are inoculated on PDA plates and incubated at $28 \pm 2{ }^{\circ} \mathrm{C}$ for 7 10 days (Yamauchi, et al., 2004). The potato dextrose broth (PDB) is used to prepare the primary inocula. The concentration of the Fusarium spore suspension concentration is determined with a haemocytometer and adjusted with sterile distilled water to a final concentration of $1 \times 10^{6}$ spores per $\mathrm{ml}$. The tomato seeds of DMT-2 varieties are obtained from the Department of Horticulture, University of Agricultural Sciences, Dharwad. The seeds are sown in seedling trays filled with coconut pith compost and watered regularly. 30 days old healthy seedlings are inoculated with the pathogen by root dip method.

In vitro Selection of antagonistic actinobacteria against Fusarium oxysporum f. sp. lycopersici

In primary screening a total of 80 actinobacteria are screened for their antagonistic activity against Fusarium oxysporum f. sp. lycopersici by cross steak method as per the protocols of Rahman et al., (2011). Actinobacterial isolates are streaked at the centre of SCBA media plates, and then plates are incubated at $28{ }^{\circ} \mathrm{C}$ for seven days after that fungal disc of $6 \mathrm{~mm}$ diameter is bored at $90^{\circ}$ angles on both sides at defined length. From the primary screening, potent isolates are subjected to the secondary screening on SCA plates. Media plate with pathogen alone is maintained as a control. All these plates are incubated at room temperature and observed for the inhibition of the growth of the pathogen. Observations are taken six days after pathogen inoculation. The zone of inhibition is measured (Biratu et al., 2013). and colony growth inhibition (\%) is calculated by using the formula: $\mathrm{PI}=(C-$ $T) / C \times 100$, where PI is the percent inhibition, 
$C$ is the colony growth of the pathogen in control, and $T$ is the colony growth of the pathogen in dual culture. All isolates are tested in triplicate.

\section{Application of G. faiculatum culture}

The plastic pots are filled with soil (500 g per pot), and tomato seeds treated with the actinobacteria are sown (as indicated in section 3.9.2.1). G. fasiculatum inocula@25 $\mathrm{g} \operatorname{pot}^{-1}$ (125 spores/50 $\mathrm{g}$ of soil) is mixed thoroughly with the top 10 to $15 \mathrm{~cm}$ of the soil (Habte and Osorio, 2002). There are four treatments with eight replications. Plants are maintained in a greenhouse and analyzed for per cent root colonization.

\section{Per cent root colonization}

The mycorrhizal root colonization is determined as per the procedure proposed by Philips and Hayman (1970) and the percentage of roots colonized by mycorrhizae is calculated by the formula given by Nicolson (1960):

Number of root segments positive for colonization

Per cent root

Colonization = ----------------------------- x 100

Total number of root segments

In vivo screening of actinobacterial and $G$. fasiculatum for inhibitory activity against F. oxysporum f. sp. lycopersici MB6-1

Actinobacteria isolates which showed significant inhibition of $F$. oxysporum f. sp. lycopersici MB6-1 in vitro are selected for in vivo screening. Three selected actinobacteria isolates viz, AUDT 699, AUDT 693 and AUDT 626 and G. fasiculatum are used for the greenhouse experiment.

\section{Raising of tomato plants}

For in vivo study, tomato variety of DMT-2, which is known to be susceptible to $F$. oxysporum f. sp. lycopersici MB6-1 is used. Tomato seeds are sown in small pots containing sterilized soil and sand mixture in 3:1 proportion. Completely randomised block design (CRBD) is used as a statistical design.

\section{Method of application of actinobacteria isolates}

Two methods are followed for the application of actinobacteria.

\section{Seed priming}

Tomato seeds are surface sterilized with 0.02 per cent mercuric chloride for $5 \mathrm{~min}$ and rinsed thoroughly in sterile water. The priming of the seed is done by soaking seeds in culture broth of actinobacterial isolates with 1 per cent sterilized carboxy methyl cellulose $(\mathrm{CMC})$ as a sticker.

The suspensions are incubated for $10 \mathrm{~min}$ to facilitate attachment of bacterial cells to the seed coat. Later, the seeds are allowed to dry and then sown (Ramanathan et al., 2000).

Preparation and application of the lignite based culture

The lignite based culture is prepared by mixing the culture growth of actinomycetes isolates with sterile lignite at 1:3 ratios and soil application is done at a rate of $100 \mathrm{mg}$ of lignite based culture/kg of soil (Ramamoorthy et al., 2002).

The foliar application is performed with 2 per cent lignite based culture at fifteen days interval i.e. 15 and 30 days after sowing (DAS) (Bahadur et al., 2007).

\section{Method of application of $G$. fasciculatum inoculum}

The plastic pots are filled with soil $(500 \mathrm{~g}$ $\left.\operatorname{pot}^{-1}\right)$, G. fasiculatum inoculum @ $25 \mathrm{~g} \mathrm{pot}^{-1}$ 
(125 spores/50 $\mathrm{g}$ of soil) mixed thoroughly with the top 10 to $15 \mathrm{~cm}$ of the soil and then tomato seeds treated with the actinobacteria are sown. There are eight treatments with eight replications. Plants are maintained in a green house.

Challenge inoculation of $F$. oxysporum $f$. sp. lycopersici MB6-1

Tomato seedlings are inoculated with $F$. oxysporum f. sp. lycopersici MB6-1 by using spore suspension with conidial concentration of $1 \times 10^{6}$ conidia/ml by root dip method (Anil and Garampalli, 2013).

Thirty days old healthy seedlings are uprooted carefully preserving root integrity, shaken to remove the adhering soil particles and washed gently under tap water. The root tip $(1 \mathrm{~cm})$ is trimmed with a sterile scissor and submerged for $30 \mathrm{~min}$ in the conidial suspension. The inoculated seedlings and control are individually planted in their respective pots (Nirmaladevi and Shrinivas, 2012).

\section{Monitoring of the disease}

The monitoring of wilt disease is done by taking the observation for symptom on $5^{\text {th }}$ and $6^{\text {th }}$ days after inoculation of the pathogen. The per cent disease incidence is calculated using the formula given by Shelly et al., (2005):

Per cent

Number of plants infected

Disease incidence $=$------------------------ x 100

Total numbers of plants

\section{Results and Discussion}

Isolation of Fusarium from infested samples and pathogenicity

The pathogen is first confirmed by observing the typical colony morphology on PDA, Fusarium isolated from the stem of diseased tomato plants formed a hyaline, branching mycelium that is white to grey (Fig. 1). Isolates formed macroconidia as eliptical, gradually pointed or curved edges and the septation is of 3 to 5 . The microconidia are usually aseptate or single septate (Fig. 2). The virulent Fusarium isolates are inoculated to 30 days old tomato seedlings by root injury inoculation technique. Initially, drooping down of youngest leaves followed by wilting of the whole plant after five to six days is observed (Fig. 3). Among the five isolates, Fusarium (MB6-1, MB6-2, MB6-3, MB6-4 and MB6-5), MB6-1 isolate showed high disease severity. Therefore, MB6-1 Fusarium isolate is used for further work.

Antimicrobial activity of the actinobacterial isolates against Fusarium oxysporum f. sp. lycopersici MB6-1

During primary screening six actinobacteria isolates showed inhibition to Fusarium oxysporum f. sp. lycopersici MB6-1. These isolates are used for secondary screening. Six isolates that showed inhibitory activity in primary screening are selected for secondary screening. Both the diameter and annular radius of the inhibition zone shown by isolates are measured and analyzed. All the isolates showed a significant difference in their inhibition against the pathogen. Isolate AUDT 626 is the most potent isolate followed by AUDT 699 and AUDT 693 (Table 1). The three isolate are selected further for cultural analysis.

Influence of the actinobacteria on the percent colonization $G$. fasiculatum in tomato

The observations on $G$. fasiculatum spore count are carried out at 30 days after the sowing (DAS). The percent root colonization is recorded at 30 DAS and presented in table 3 . Plants treated with only $G$. fasiculatum showed $52.5 \%$ of root colonization, whereas 
plants treated with $G$. fasiculatum along with actinobacteria AUDT 626 showed 58.8\% root colonisation. Hence, AUDT 626 isolate showed resistance to disease compared to other two isolates (AUDT 699, AUDT 693) alone. Further, AUDT $626+G$. fasiculatum induced high disease resistance as compared to other two isolates in association with $G$. fasiculatum. Therefore, actinobacterial isolate AUDT 626 individually and in association with $G$. fasiculatum is used for transcript analysis (Table 2).

The role of actinobacteria in association with G. fasiculatum in tomato Fusarium wilt disease resistance

When three antinobacteria isolates AUDT 626, AUDT 699 and AUDT 693 separately and along with $G$. fasiculatum are screened against wilt disease in tomato, it is found that plants treated with actinobacterial isolates showed low diseased symptoms whereas plants treated with actinobacterial isolates in association with the $G$. fasiculatum lower disease symptoms compared to uninoculated one. All the three isolates alone and in association with $G$. fasiculatum showed significant disease control over pathogen control. Though AUDT 626 (Fig. 3) alone is found effective (25\% disease incidence), AUDT 626 in association with $G$. fasiculatum (Fig. 4) showed higher efficiency (no disease incidence). The plants treated with the only pathogen as expected showed $100 \%$ disease symptom (Table 3 ).

Role of actinobacteria in association with G. fasiculatum in tomato Fusarium wilt disease resistance and plant growth promotion

\section{Root length}

Individual inoculation of actinobacteria and G. fasiculatum has improved the root growth significantly (Table 4). However, in the presence of the pathogen, the interaction is insignificant in term of the length. AUDT 626 caused the highest increase $(12.6 \mathrm{~cm})$ in root length compared to control $(3.1 \mathrm{~cm})$ and only pathogen infected plant $(1.7 \mathrm{~cm})$. The inoculation of $G$. fasiculatum has increased the root length $(14.7 \mathrm{~cm})$ significantly over the control $(3.1 \mathrm{~cm})$, only pathogen $(1.7 \mathrm{~cm})$ inoculated and actinobacteria $(7-12.6 \mathrm{~cm})$ inoculated treatments.

The interaction of actinobacteria and $G$. fasiculatum to the pathogen infected plants did not show any significant change in the root length over pathogen plants. However, in the presence of AUDT 626 + pathogen (2.1 $\mathrm{cm})$ and $G$. fasiculatum + pathogen $(1.96 \mathrm{~cm})$, there is no significant difference over the uninoculated control $(3.1 \mathrm{~cm})$.

Co-inoculation of actinobacteria (AUDT 626, AUDT 699) and G. fasiculatum improved the plant root length over individual inoculation which is not significantly different from those of the pathogen inoculated.

\section{Shoot length}

Individual inoculation of actinobacteria and G. fasiculatum has increased the shoot length significantly over the uninoculated control and pathogen infected control. Amongst the actinobacteria, AUDT 626 has caused the highest increase $(14.0 \mathrm{~cm})$. Inoculation of $G$. fasiculatum showed significantly higher shoot length $(15.3 \mathrm{~cm})$ than the actinobacteria AUDT $626(14.0 \mathrm{~cm})$. The inoculation of actinobacteria to AUDT 626, AUDT 693, AUDT 699 and G. fasiculatum has improved the shoot length $(11.70 \mathrm{~cm}, 8.00 \mathrm{~cm}, 7.86$ and $10.54 \mathrm{~cm}$, respectively) significantly over pathogen inoculated plants $(6.6 \mathrm{~cm})$.

The co-inoculation of the G. fasiculatum and actinobacteria (AUDT 6262, AUDT 693 and 
AUDT 699) also resulted in significant increase in shoot length $(16.9 \mathrm{~cm}, 10.88 \mathrm{~cm}$, $11.34 \mathrm{~cm}$, respectively) over individual inoculation of actinobacteria AUDT 6262, AUDT 693, AUDT 699 and G. fasiculatum $(11.70 \mathrm{~cm}, 8.00 \mathrm{~cm}, 7.86$ and $10.54 \mathrm{~cm}$, respectively).

\section{Total dry weight of the plant}

Individual inoculation of actinobacteria AUDT 626 and G. fasiculatum has increased the total dry weight significantly over the uninoculated control and pathogen inoculated control. AUDT 626 caused the highest increase $(90 \mathrm{mg})$ in total dry weight compared to control $(30 \mathrm{mg})$ and only pathogen infected $(20 \mathrm{mg})$.

The inoculation of $G$. fasiculatum has significantly increased the total dry weight $(96 \mathrm{mg})$ over the uninoculated control (30 $\mathrm{mg})$ and only pathogen $(20 \mathrm{mg})$ inoculated.
The interaction of AUDT $626+G$. fasiculatum with that of the pathogen infected plants showed a significant increase in the total dry weight $(80 \mathrm{mg})$ over the uninoculated control and only pathogen inoculated plants.

Co-inoculation of actinobacteria AUDT 626, AUDT 699 and AUDT 693 and $G$. fasiculatum high dry weight $(132 \mathrm{mg}, 110$ $\mathrm{mg}, 70 \mathrm{mg}$, respectively) significantly over their respective individual inoculation of actinobacteria which is significantly different from those of the uninoculated control, and the pathogen inoculated plants.

Tomato is infected by a number of pathogens, including $F$. oxysporum f. sp. lycopersici (Sacc.), the causal agent of Fusarium wilt of tomato (Ignjatov et al., 2015), which is one of the most important pathogen species on tomato (Sahi and Khalid, 2007).

Table.1 Zone of inhibition of F. oxysporum $\mathrm{f}$. sp. lycopersici MB6-1 by actinobacterial isolates

\begin{tabular}{|c|l|c|}
\hline S1. No. & Actinobacteria isolate & Zone of inhibition $(\mathrm{mm})$ \\
\hline 1 & AUDT 699 & 30.59 \\
\hline 2 & AUDT 697 & 20.24 \\
\hline 3 & AUDT 726 & 29.5 \\
\hline 4 & AUDT 693 & 30.21 \\
\hline 5 & AUDT 626 & 30.99 \\
\hline 6 & AUDT 701 & 19.70 \\
\hline & S. Em. + & 0.93 \\
\hline & C.D. at 5\% & 2.93 \\
\hline
\end{tabular}

Table.2 Percent of root colonization by G. fasiculatum in tomato plant

\begin{tabular}{|c|c|}
\hline \multicolumn{1}{|c|}{ Treatments } & \% Root colonization \\
\hline Control & 00.0 \\
\hline G. fasiculatum & 52.5 \\
\hline AUDT 626 + G. fasiculatum & 58.8 \\
\hline AUDT 699+ G. fasiculatum & 56.3 \\
\hline AUDT 693 + G. fasiculatum & 53.0 \\
\hline S. Em. + & 0.16 \\
\hline C.D. at 5 $\%$ & 0.46 \\
\hline
\end{tabular}




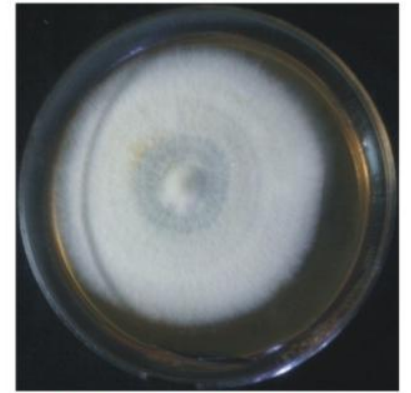

Fig.1: Growth of the Fusarium oxysporum f. sp. lycopersici MB6-1 on PDA

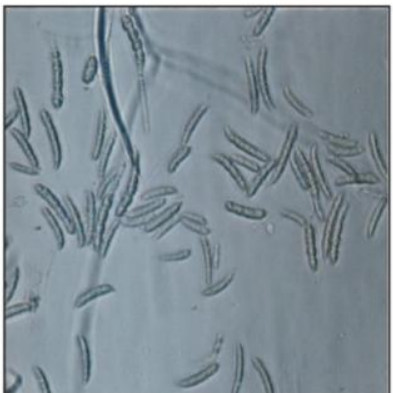

Fig.2: Microconidia and macroconidia of Fusarium oxysporum f. sp. lycopersici MB6-1

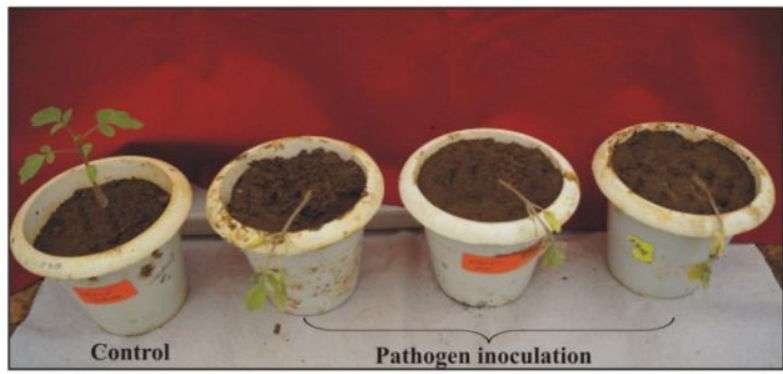

Fig.3: Tomato plant showing sever wilt symptoms when inoculated with the Fusarium, uninoculated control.

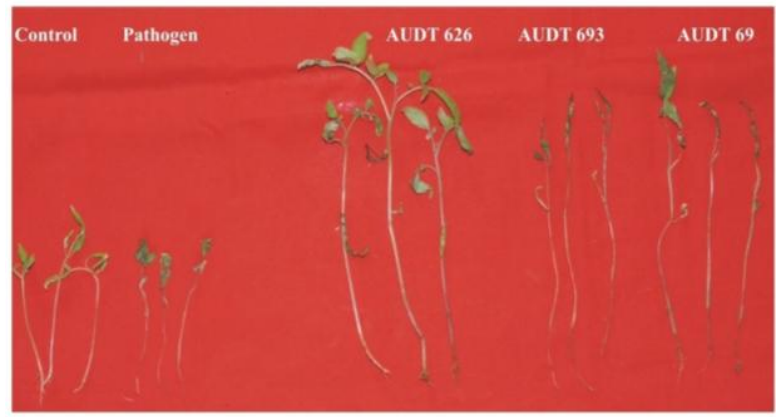

Fig. 4: Comparison of control, pathogen treated, AUDT 626, AUDT 699 and AUDT 693 in challenge inoculation of Fusarium in tomato plant

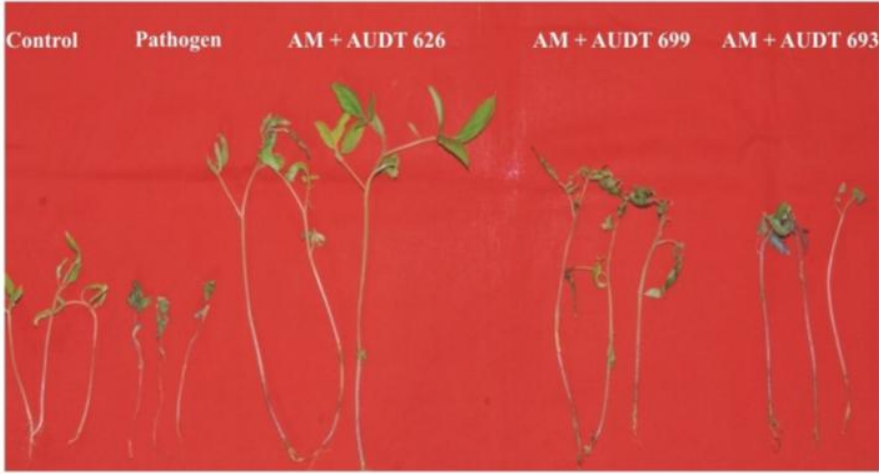

Fig. 5: Comparison of control, pathogen treated, AM + AUDT 626, AM + AUDT 699 and AM + AUDT 693 in challenge inoculation of Fusarium in tomato plant 
Table.3 Percent disease incidence in tomato plants inoculated with actinobacteria, $G$. fasiculatum and F. oxysporum f. sp. lycoprsici MB6-1 tomato

\begin{tabular}{|c|l|c|}
\hline Sl. No. & \multicolumn{1}{|c|}{ Treatments } & Percent disease incidence \\
\hline 1 & G. fasiculatum + AUDT 626+ Pathogen & 0 \\
\hline 2 & G. fasiculatum + AUDT 699 + Pathogen & 55 \\
\hline 3 & G. fasiculatum + AUDT 693 + Pathogen & 80 \\
\hline 4 & G. fasiculatum + Pathogen & 70 \\
\hline 5 & AUDT 626 + Pathogen & 25 \\
\hline 6 & AUDT 699 + Pathogen & 85 \\
\hline 7 & AUDT 693 + Pathogen & 92 \\
\hline 8 & Pathogen only (disease control) & 100 \\
\hline 9 & Control & 0 \\
\hline
\end{tabular}

Table.4 Plant growth parameters as influenced by actinobacteria and G. fasiculatum with Fusarium oxysporum f.sp. lycopersici MB6-1 inoculation in tomato 36 DAI under greenhouse condition

\begin{tabular}{|l|c|c|c|}
\hline \multicolumn{1}{|c|}{ Treatments } & $\begin{array}{c}\text { Root length } \\
(\mathrm{cm})\end{array}$ & $\begin{array}{c}\text { Shoot length } \\
(\mathrm{cm})\end{array}$ & $\begin{array}{c}\text { Total dry } \\
\text { weight }(\mathrm{mg})\end{array}$ \\
\hline Control & 3.1 & 6.82 & 30 \\
\hline Pathogen & 1.7 & 6.6 & 20 \\
\hline AUDT 626 & 12.6 & 14 & 90 \\
\hline AUDT 693 & 7 & 9.5 & 26 \\
\hline AUDT 699 & 8.8 & 10.9 & 20 \\
\hline G. fasiculatum & 14.7 & 15.3 & 96 \\
\hline AUDT 626+ Pathogen & 2.1 & 11.7 & 40 \\
\hline AUDT 693 + Pathogen & 1.5 & 8 & 14 \\
\hline AUDT 699+ Pathogen & 1.9 & 7.86 & 16 \\
\hline G. fasiculatum + Pathogen & 1.96 & 10.54 & 50 \\
\hline AUDT 626+ G. fasiculatum & 22 & 18.5 & 132 \\
\hline AUDT 693+ G. fasiculatum & 11.8 & 12.4 & 70 \\
\hline AUDT 699+ G. fasiculatum & 21.30 & 12.8 & 110 \\
\hline AUDT 626 + G. fasiculatum + Pathogen & 3.18 & 16.9 & 80 \\
\hline AUDT 693+ G. fasiculatum + Pathogen & 1.86 & 10.88 & 3 \\
\hline AUDT 699 + G. fasiculatum + Pathogen & 2.58 & 11.34 & 50 \\
\hline S. Em \pm & 0.39 & 0.28 & 0.37 \\
\hline C. D. at 5\% & 1.10 & 0.79 & 1.06 \\
\hline
\end{tabular}

The result of the experiments done to understand the interaction of actinobacteria and Glomus fasiculatum in the presence of Fusarium oxysporum f. sp. lycopersici MB6-1 is discussed herein.

In the present study, the pathogen is isolated from the infested plant sample collected from the fields of University of Agriculture Sciences, Dharwad. Isolate samples are surface sterilized and incubated on PDA plate at $28{ }^{\circ} \mathrm{C}$ for three days. Colonies are identified as $F$. oxysporum based on morphological characteristics of the macroconidia, microconidia, chlamydospores and colony growth traits (Nirmaladevi and Shrinivas, 2012). To check the virulence of the Fusarium isolates, pathogenesis test is carried out using five isolates. After four to five days of inoculation, it is observed that five isolates 
showed wilting symptoms, but the degree of infection is variable. The isolated, MB6-1 showed the highest virulence and is selected as the most virulent isolate for further studies.

In the present study, primary screening is done using cross streak method for all 80 actinobacterial isolates against the test pathogen, $F$. oxysporum f. sp. lycopersici MB6-1. Of all the tested isolates, six isolates showed inhibition effect on $F$. oxysporum $\mathrm{f}$. sp. lycopersici MB6-1. In secondary screening, six isolates AUDT 701, AUDT 699, AUDT 697, AUDT 726, AUDT 693 and AUDT 626 showed inhibitory activity against the target pathogen. Inhibition zone up to $30.99 \mathrm{mM}$ diameter is observed in AUDT626 which is the highest of all the six. Thus it indicates that the actinobacterial isolates possessed antibacterial activity against the target pathogen and can be used as a component of integrated disease management practices. The antibacterial activity exhibited by actinobacteria may be due to the secretion of extracellular antimicrobial compounds. Antibiotics are known to be produced in the SCA media plates (Rahman et al., 2011).

Some of the naturally antagonistic microorganisms, Bacillus species and Pseudomonas fluorescens (Anuratha and Gnanamanickam, 1990, Xue et al., 2009), Stenotrophomonas maltophilia (Messiha et al., 2007), Streptomyces griseus (Palaniyandi et al., 2013) is shown to exhibit antagonistic activity against Fusarium and have been used as biocontrol agent against the wilt disease. Other bacteria including Bacillus mesenteriacus, B. megaterium, B. subtilis, B. mycoides and Erwinia have been reported to be active biological control agents (Kelman, 1953). In the present study, a wide range of response of tomato plants inoculated with test isolates alone and in association with $G$. faiculatumagainst tomato wilt disease pathogen is noticed. Among the test isolates, inoculation of three actinobacterial isolates (AUDT 626 and AUDT 699) showed a reduction in disease symptoms. The development of disease symptoms in AUDT 626 individual inoculated plants showed 25 per cent at $36 \mathrm{DAI}$; in AUDT $626+G$. fasiculatum showed no disease symptoms. Whereas it is 100 per cent in disease control and 85 and 92 per cent in other test isolates alone (AUDT 693 and AUDT 699 respectively) whereas 55 per cent in $G$. fasiculatum + AUDT 699 and 80 per cent in G. fasiculatum + AUDT 699 treated plant.

It has been reported that G. fasiculatum, Plant Growth Promoting Rhizobacteria (PGPR) and actinomycetes, as rhizospheric microorganisms play an important role in promoting plant growth and protection against plant pathogens. These have participated in the direct or indirect enhancement of plant growth through their individual effects if any. However, the detrimental effect of the entire three groups with each other depends upon the species involved (Kamal et al., 2015). The inoculation of $G$. fasiculatum exhibited a reduction in root necrosis in tomato due to $F$. oxysporum f. sp. lycopersici MB6-1. The affect is more pronounced when $G$. fasiculatum is inoculated four weeks before $F$. oxysporum f. sp. lycopersici MB6-1. G. fasiculatum also is known to reduce the number of propagules of pathogenic fungi (Mukerji et al., 1999). G. fasciculatum and G. macrocarpum have been reported to suppress apple replant disease caused by phytotoxic myxomycetes (Catska, 1994).

Three actinobacterial isolates AUDT 626, AUDT 699 and AUDT 697 alone and actinobacterial isolates in association with $G$. fasiculatum contributed to the improvement of plant growth parameters like, shoot length, root length, total dry weight in tomato.

The application of the test isolates of actinobacteria and $G$. fasiculatum inocula 
resulted in the observation of promotion of all tested plant growth parameters. The root length of plant inoculated with test isolates ranged from 1.50 to $12.6 \mathrm{~cm}$ whereas test isolates in association with $G$. fasiculatum ranged from 1.86 to $22 \mathrm{~cm}$. It is however, 1.7 $\mathrm{cm}$ in disease control and $3.1 \mathrm{~cm}$ in healthy control. After $36 \mathrm{DAI}$, it is observed that, there are 123 per cent increase in root length of plant inoculated with AUDT $626+$ pathogen, $187 \%$ in G. fasiculatum + AUDT 626 + pathogen which is followed by $(89.4$ $\%)$ AUDT 699 + pathogen, (151.7\%) $G$. fasiculatum + AUDT 699 and (91 \%) G. fasiculatum + AUDT $693+$ pathogen inoculation over disease control.

The shoot length of plant inoculated with actinobacterial isolates alone ranged from 9.5 to $14 \mathrm{~cm}$ highest shoot length where as it ranged from 12.4 to $18.5 \mathrm{~cm}$. It is however, $6.6 \mathrm{~cm}$ in disease control and $6.82 \mathrm{~cm}$ in healthy control. There is 177 per cent increase in shoot length in AUDT 626 + pathogen treated plant, 256 per cent increase in AUDT $626+G$. fasiculatum + pathogen followed by (119\%) AUDT 699 + pathogen, (172\%) G. fasiculatum + AUDT 699 + pathogen, (121 $\%)$ AUDT 693 + pathogen and (164\%) AUDT $693+$ G. fasiculatum + pathogen over disease control.

The total dry weight for plant inoculated with actinobacterial isolate ranged from $1.6 \mathrm{mg}$ to $9 \mathrm{mg}$ whereas it ranged from $3 \mathrm{mg}$ to $13 \mathrm{mg}$ in plants inoculated with $G$. fasiculatum + actinobacterial isolates. After $36 \mathrm{DAI}$, it is observed that, there is 300 per cent increase in dry weight of plant inoculated with AUDT 626 + pathogen alone, 400 per cent in AUDT $626+G$. fasiculatum + pathogen which is followed by $(250 \%)$ AUDT $699+G$. fasiculatum and AUDT $693+G$. fasiculatum (150\%) isolates over disease control. As observed among the three (AUDT 699, AUDT 626 and AUDT 693) isolates of actinobacteria alone treated with Fusarium wilt, AUDT 626 alone showed high (75\%) disease resistance. The isolate AUDT 626 in association with $G$. fasiculatum is treated in challenged inoculation with Fusarium oxysporum f. sp. lycopersici MB6-1 showed $100 \%$ of disease resistance where as AUDT 699 and AUDT 693 in association with $G$. fasiculatum treated with Fusarium oxysporum f. sp. lycopersici MB6-1showed lesser resistance (45\% and $20 \%$ respectively) in comaparision with plants treated with AUDT 626 alone $+F$. oxysporum f. sp. lycopersici MB6-1 and also in the plants treated with AUDT $626+G$. fasiculatum $(75 \%$ and 100 $\%$ respectively) as mentioned in table 4 . Finally, it is clear that, microbial inoculation with Streptomyces, mycorrhizal fungi or both decreased or prevent fungal infection or/and enhanced plant growth.

Consortia of $G$. fasiculatum and actinobacteria proved to be potent biocontrol agent apart from inducing disease resisance in plant also promoted the plant growth such as shoot length, root length and total dry weight.

The application of mixed cultures of actinobacteria along with arbascular mycorrhiza is a simple methodology and ecofriendly to control wilt disease of tomato compared to harmful chemical pesticide and fertilers.

\section{Future line of work}

Future work can be taken by identification and confirmation of the compound responsible for controlling the disease. Field trial can be taken out to help tomato.

\section{Acknowledgments}

I would like to thank ICAR Niche area of excellence for funding my project, Dr. P. Jones Nirmalnath, Professor, Weed Control Scheme, MARS, University of Agricultural Sciences, Dharwad, Karnataka, India. 


\section{References}

Aghighi, S., Shahidi Bonjar, G.H. and Saadoun, I., 2004. First report of antifungal properties of a new strain of Streptomyces plicatus (strain101) against four Iranian phytopathogenic isolates of Verticillium dahliae, a new horizon in biocontrol agents. Biotechnology (Faisalabad), 3(1), pp.9097.

Anuratha, C. S., and Gnanamanickam, S. S., 1990, Biological control of bacterial wilt caused by Pseudomonas solanacearum in India with antagonistic bacteria. Plant Soil, 124: 109-116.

Bahadur, A., Singh, U. P., Sarma, B. K., Singh, D, P., Singh, K. P. and Singh, A., 2007, Foliar application of plant growth-promoting rhizobacteria increases antifungal compounds in pea (Pisum sativum) against Erysiphe pisi. Mycobiol, 35(3): 129-134.

Biratu, K. S., Selvaraj, T. and Hunduma, T., 2013, in vitro evaluation of actinobacteria against tomato bacterial wilt (Ralstonia solanacearum) in West Showa, Ethiopia. J. Plant Pathol Microb., 4(1): 157-174.

Catska, V., 1994, Interrelationships between vesicularG. faiculatum and rhizosphere microflora in apple replant disease. Biologia Plantarum., 36: 99-104.

Coronado, E., and Espallargas, G.M., 2013. Dynamic magnetic MOFs. Chemical Society Reviews, 42(4), pp.1525-1539.

Habte, M., and Osorio, N. W., 2001, Synergistic Influence of an arbuscular mycorrhizal fungus and a $\mathrm{P}$ solubilizing fungus on growth and $\mathrm{P}$ uptake of Leucaena leucocephala in an Oxisol. Arid Land Res. Manage., 15: 263-274

Kamal, R., Gusain, Y. S., Sharma, I. P., Sharma, S. and Sharma, A. K., 2015, Impact of arbuscular mycorrhizal fungus, Glomus intraradices, Streptomyces and Pseudomonas spp. strain on finger millet (Eleusine coracana L.) korchara under water deficit condition. Afr. J. Biotechnol., 14(48):3219-3227.

Nawar, L. S., 2016, Interactions between vascular arbuscular mycorrhizal fungi and streptomyces as biocontrol agent for tomato damping-off disease caused by Rhizoctonia Solani Kuhn, IOSR-JPBS., 11(6): 89-96.
Nicolson, T. H., 1960, Mycorrhiza in the Gramineae: II. Development in different habitats, particularly sand dunes. Transact. British Mycol. Soc., 43(1): 132-145.

Nirmaladevi, D., and Srinivas, C., 2012, Cultural, morphological, and pathogenicity variation in Fusarium oxysporum f. sp. lycopersici causing wilt of tomato. Batman Univ. J. Life Sci., 2(1): 231-235.

Ntalli, N.G., and Menkissoglu-Spiroudi, U., 2011. Pesticides of botanical origin: a promising tool in plant protection. In Pesticides-Formulations, Effects, Fate. InTech.

Phillips, J. M., and Hayman, D. S., 1970, Improved procedures for clearing and staining parasites and vesicular-arbuscular mycorrhizal fungi for rapid assessment of infection. Trans. Br. Mycol. Soc., 55: $158-161$.

Rahman, M. A., Islam, M. Z. and UI Islam, M. A., 2011, Antibacterial activities of actinomycete isolates collected from soils of Rajshahi, Bangladesh. Int. Biotechnol. Res., 2: 1-6.

Ramamoorthy, V., Raguchander, T. and Samiyappan, R., 2002, Induction of defense- related proteins in tomato roots treated with Pseudomonas fluorescens Pf1 and Fusarium oxysporum f. sp. lycopersici. Plant Soil, 239: 55-68.

Ramanathan, A., Samiyappan, R. and Vidhyasekaran, P., 2000, Induction of defense mechanisms in green gram leaves and suspension cultured cells by Macrophomina phaseolina and its elicitors. $J$. Plant Dis. Protect., 107: 245- 257.

Sahi, I. Y., and Khalid, A. N., 2007, In vitro biological control of Fusarium oxysporum causing wilt in Capsicum annuum. Mycopath, 5(2): 85-88.

Shelly, P., Kushwaha, C. M., Mishra, A. K., Singh, V., Jain, R. K. and Varma, A., 2005, Engineering tomato for resistance to tomato leaf curl disease using viral REP gene sequences. Plant Cell. Tiss. Org., 83: 311-318.

Xue, Q.Y., Chen, Y., Li, S. M., Chen, L. F., Ding, G. C., Guo, D. W. and Guo, J. H., 2009. Evaluation of the strains of acitnobacter and enterobacter as potential bio control agents against Ralstonia wilt of tomato. Biol. Control, 48(3): 252-258.

\section{How to cite this article:}

Anusha Suresh Gadag and Krishnaraj, P.U. 2017. Effect of Actinobacteria and Glomus fasiculatum against Fusarium oxysporum f. sp. lycopersici in Tomato Plant. Int.J.Curr.Microbiol.App.Sci. 6(9): 488-498. doi: https://doi.org/10.20546/ijcmas.2017.609.059 